\title{
Polymerase-mediated synthesis of artificial RNA-DNA metal base pairs
}

Fabienne Levi-Acobas ${ }^{a}$, Luke K. McKenzie ${ }^{a, b}$ and Marcel Hollenstein ${ }^{\star a}$

${ }^{a}$ Institut Pasteur, Université de Paris, CNRS UMR3523, Laboratory for Bioorganic Chemistry of Nucleic Acids, Department of Structural Biology and Chemistry, 28, rue du Docteur Roux, 75724 Paris Cedex 15, France

${ }^{\mathrm{b}}$ Chimie ParisTech, PSL University, CNRS, Institute of Chemistry for Life and Health Sciences, Laboratory for Inorganic Chemical Biology, 75005 Paris, France.

E-mail:marcel.hollenstein@pasteur.fr

\begin{abstract}
Metal-mediated base pairs are formed by the connection of two nucleobases via coordination to a metal cation. The resulting metal-containing duplexes have been used in a large variety of applications ranging from allosteric control of functional nucleic acids to the construction of nanowires. Recently, enzymatic approaches are being developed for the construction of metalmediated base pairs. Here, we have studied the possibility of constructing $\mathrm{Hg}^{\prime \prime}$ - and $\mathrm{Ag}^{\prime}$ mediated DNA/RNA hetero base pairs using primer extension reactions. The high kinetic and thermodynamic stabilities of metal base pairs can be harnessed to trigger the formation of multiple $\mathrm{rU}-\mathrm{Hg}^{\prime \prime}-\mathrm{dT}$ base pairs.
\end{abstract}

\section{Introduction}

Metal base pairs are structural analogs of canonical Watson-Crick pairs where the hydrogen pattern is substituted with the coordinative interaction of metal cations with the nucleobases. ${ }^{1}$, ${ }^{2}$ Metal base pairs can be constructed using the canonical nucleobases or synthetic nucleoside analogs with nucleobases that are specifically designed to serve as ligands for the specific binding of transition metal cations. ${ }^{3,4}$ These metal base pairs have advanced as promising candidates for a number of applications including the development of nanomolecular devices, ${ }^{5}$ ion sensors and biosensing devices ${ }^{6,7}$ and metal nanowires and nanodevices ${ }^{8-10}$ as well as for the allosteric control of functional nucleic acids. ${ }^{11-14}$

The formation of metal base pairs mainly occurs by annealing short synthetic oligonucleotides together with specific metal cations. While this approach has allowed the identification of numerous metal base pairs, it is restricted in oligonucleotide size and in terms of diversity of functional groups that can be explored due to the rather harsh conditions imposed by solidphase synthesis. ${ }^{15}$ Alternatively, metal base pairs can be formed via enzymatic synthesis where polymerases incorporate modified or natural nucleotides into DNA in the strict presence of metal cations. ${ }^{16-19}$

So far, most synthetic efforts have been dedicated to the identification of modified nucleobases that can act as potent ligands for metal coordination. Surprisingly, very little attention has been devoted to combining sugar and/or backbone modifications and metal base pairs, ${ }^{20-23}$ especially in the context of enzymatic synthesis. This might be ascribed to the fact that DNA 
polymerases are finely tuned biological machineries that have the capacity of strongly distinguishing dNTPs from sugar modified nucleotides including NTPs. ${ }^{24,} 25$ The strong discrimination of NTPs (by a factor of up to $10^{5}$ ) occurs by the mere presence of an additional 2'-hydroxyl moiety on NTPs which acts as a steric gate which clashes with the 2'-OH moiety of an incoming triphosphate and prevents entry into the active site of the DNA polymerase. ${ }^{25-}$ 27 Hence, most naturally occurring DNA polymerases predominantly incorporate deoxynucleoside monophosphates (dNMPs) and depending on the polymerase, insert only one ribonucleoside monophosphate every hundred thousand correct nucleotides. ${ }^{28}$ This rather strong discrimination can be alleviated by using naturally occurring polymerases that lack such a steric gate, ${ }^{29,} 30$ engineered polymerases equipped with an alternate, more permissive steric gate ${ }^{31,32}$ or by adding $\mathrm{Mn}^{2+}$ cofactors which both promote the incorporation of NTPs by DNA polymerases. ${ }^{25}$ Here, we demonstrate that the high kinetic and thermodynamic stabilities of metal base pairs ${ }^{33,34}$ can be harnessed to facilitate enzymatic RNA synthesis by DNA polymerases.

The dT-Hg"-dT undoubtedly is the most prominent and best studied metal base pair ${ }^{33}$ and both the RNA equivalent, $\mathrm{rU}-\mathrm{Hg}^{11}-\mathrm{rU},{ }^{35}$ and the chimeric RNA-DNA variant, $\mathrm{rU}-\mathrm{Hg}{ }^{\mathrm{II}}-\mathrm{dT},{ }^{36,}{ }^{37}$ have been identified. The addition of mercury cations to these mismatches leads to large thermal stabilizations of duplexes $\left(\Delta T_{\mathrm{m}}\right.$ ranging from +6 to $\left.+10^{\circ} \mathrm{C}\right)$ driven by favorable enthalpy and entropy of formation. ${ }^{38}$ These favorable assets have allowed the enzymatic construction of single ${ }^{39}$ and multiple ${ }^{40} \mathrm{dT}-\mathrm{Hg}^{11}$-dT base pairs under primer extension (PEX) reaction conditions. Similarly, silver cations have been shown to stabilize duplexes containing $\mathrm{dC}-\mathrm{dC}$ and $\mathrm{dC}-\mathrm{dA}$ mismatches $\left(\Delta T_{\mathrm{m}}=+8.3^{\circ} \mathrm{C}\right.$ and $+4.0^{\circ} \mathrm{C}$, respectively) ${ }^{41,42}$ which also could be produced enzymatically. ${ }^{43-45}$ However, the possibility of using these stable metal base pairs to form RNADNA heteroduplexes by enzymatic synthesis has never been investigated.

\section{Results and discussion}

In a first step towards this aim, we wanted to evaluate the possibility of forming RNA-DNA mixed metal base pairs on short synthetic oligonucleotides using UV melting experiments. To do so, we designed 4 different duplexes containing central rU-dT, rA-dA, rC-dA, and rC-dC mismatches using 13 nucleotide long sequences (Table 1). ${ }^{46,47}$ The thermal stability of these duplexes in the presence of $\mathrm{Ag}^{\prime}, \mathrm{Hg}^{\prime \prime}$, and a combination of $\mathrm{Hg}^{\prime \prime}$ and $\mathrm{Mn}^{\prime \prime}$ was investigated by temperature-dependent UV spectroscopy (Table 1 and Supporting Information). We have also determined the $T_{\mathrm{m}}$ values of a fully matched duplex (duplex 1 ) and a duplex containing a central $\mathrm{dT}$-dT mismatch to compare with the stability of the duplexes containing RNA-DNA mismatches. Expectedly, this analysis revealed that $\mathrm{Ag}^{\mathrm{l}}$ and $\mathrm{Hg}^{\prime \prime}$ had little incidence on the thermal stability of a fully matched duplex (duplex 1 ) and that $\mathrm{Hg}^{\prime \prime}$ could specifically stabilize a $\mathrm{dT}$-dT mismatch by formation of a metal base pair $\left(\Delta T_{\mathrm{m}}=+9.8^{\circ} \mathrm{C}\right.$; duplex 2$)$. The insertion of an rU-dT mismatch (duplex 3 ) led to a further decrease in duplex stability compared to the system containing a dT-dT mismatch $\left(\Delta T_{\mathrm{m}}=-3.0^{\circ} \mathrm{C}\right)$ and the presence of $\mathrm{Hg}^{\prime \prime}$ could substantially compensate for this loss of thermal stability $\left(\Delta T_{\mathrm{m}}=+8.3^{\circ} \mathrm{C}\right)$. Hence, the dT- $\mathrm{Hg}^{\prime \prime}-$ $\mathrm{dT}$ and $\mathrm{rU}-\mathrm{Hg}^{\prime \prime}-\mathrm{dT}$ base pairs stabilize mismatched duplexes with comparable efficiencies $\left(\Delta T_{\mathrm{m}}\right.$ $=+9.8$ and $+8.3^{\circ} \mathrm{C}$, respectively). The introduction of $\mathrm{rA}-\mathrm{dA}, \mathrm{rC}-\mathrm{dA}$, and $\mathrm{rC}-\mathrm{dC}$ mismatches leads to a similar destabilization as observed between duplexes 2 and $3\left(\Delta T_{\mathrm{m}}\right.$ ranging from 3.0 to $-4.0^{\circ} \mathrm{C}$ ). The addition of $\mathrm{Ag}^{\prime}$ leads to marked increases in $T_{\mathrm{m}}$ values of the systems containing $\mathrm{rC}-\mathrm{dA}$ (duplex 5) and $\mathrm{rC}-\mathrm{dC}$ (duplex 6) mismatches $\left(\Delta T_{\mathrm{m}}=+3.8\right.$ and $+4.3^{\circ} \mathrm{C}$, respectively) but appears to be thermoneutral in the case of duplex 4 that contains an $\mathrm{rA}-\mathrm{dA}$ mismatch $\left(\Delta T_{\mathrm{m}}=1.0^{\circ} \mathrm{C}\right)$. Hence, the gain in duplex stabilization generated by the formation of an $\mathrm{rC}-\mathrm{Ag}^{\mathrm{I}}-\mathrm{dC}$ pair appears to be much reduced compared to that of the corresponding $\mathrm{dC}-\mathrm{Ag}^{\mathrm{I}}$ $\mathrm{dC}$ base pair $\left(\Delta T_{\mathrm{m}}\right.$ of $+4.3^{\circ} \mathrm{C}$ and $+8.3^{\circ} \mathrm{C},{ }^{41}$ respectively) and compares to the stabilization 
imparted by an all-RNA rC-Ag'-rC pair $\left(\Delta T_{\mathrm{m}}=+4.0^{\circ} \mathrm{C}\right) \cdot{ }^{37} \mathrm{On}$ the other hand, the $\mathrm{rC}-\mathrm{Ag}^{\prime}-\mathrm{dC}$ and dC-Ag'-dC result in comparable increases in thermal stabilities $\left(\Delta T_{\mathrm{m}}\right.$ of $+3.8^{\circ} \mathrm{C}$ and $+3.5^{\circ} \mathrm{C},{ }^{48}$ respectively).

Table 1. Oligonucleotide sequences containing mismatches and effect of $\mathrm{Hg}^{\prime \prime}$ and $\mathrm{Ag}^{\prime}$ on duplex stability $\left(T_{\mathrm{m}}\right)$.

\begin{tabular}{|c|c|c|c|c|}
\hline Duplex & Sequences & Metal cation & $T_{\mathrm{m}}\left({ }^{\circ} \mathrm{C}\right)$ & $\Delta T_{\mathrm{m}}\left({ }^{\circ} \mathrm{C}\right)$ \\
\hline Duplex 1 & $\begin{array}{l}\text { 5'-GAGGGTATGAAAG } \\
\text { 3'-CTCCCATACTTTC }\end{array}$ & - & $50.6(4)$ & - \\
\hline Duplex 1 & $\begin{array}{l}\text { 5'-GAGGGTATGAAAG } \\
\text { 3'-CTCCCATACTTTC }\end{array}$ & $\mathrm{Ag}^{\mathrm{I}}$ & $51.4(1)$ & $+0.8(2)$ \\
\hline Duplex 1 & $\begin{array}{l}\text { 5'-GAGGGTATGAAAG } \\
\text { 3'-CTCCCATACTTTC }\end{array}$ & $\mathrm{Hg} "$ & $50.3(5)$ & $-0.3(3)$ \\
\hline Duplex 2 & $\begin{array}{l}\text { 5'-GAGGGTTTGAAAG } \\
\text { 3'-CTCCCATACTTTC }\end{array}$ & - & $41.8(2)$ & - \\
\hline Duplex 2 & $\begin{array}{l}\text { 5'-GAGGGTTTGAAAG } \\
\text { 3'-CTCCCATACTTTC }\end{array}$ & $\mathrm{Hg}$ & $51.6(1)$ & $+9.8(2)$ \\
\hline Duplex 2 & $\begin{array}{l}\text { 5'-GAGGGTTTGAAAG } \\
\text { 3'-CTCCCATACTTTC }\end{array}$ & $M n^{\prime \prime}$ & $41.4(2)$ & $-0.4(2)$ \\
\hline Duplex 2 & $\begin{array}{l}\text { 5'-GAGGGTTTGAAAG } \\
\text { 3'-CTCCCATACTTTC }\end{array}$ & $\mathrm{Hg}^{\prime \prime}, \mathrm{Mn}^{\prime \prime}$ & $50.8(1)$ & $+9.0(2)$ \\
\hline Duplex 3 & $\begin{array}{l}\text { 5'-GAGGGTrUTGAAAG } \\
\text { 3'-CTCCCATACTTTC }\end{array}$ & - & $38.8(2)$ & - \\
\hline Duplex 3 & $\begin{array}{l}\text { 5'-GAGGGTrUTGAAAG } \\
\text { 3'-CTCCCATACTTTC }\end{array}$ & $\mathrm{Hg} "$ & $47.1(2)$ & $+8.3(2)$ \\
\hline Duplex 3 & $\begin{array}{l}\text { 5'-GAGGGTrUTGAAAG } \\
\text { 3'-CTCCCATACTTTC }\end{array}$ & $M n^{\prime \prime}$ & $39.0(1)$ & $+0.2(2)$ \\
\hline Duplex 3 & $\begin{array}{l}\text { 5'-GAGGGTrUTGAAAG } \\
\text { 3'-CTCCCATACTTTC }\end{array}$ & $\mathrm{Hg}^{\prime \prime}, \mathrm{Mn}^{\prime \prime}$ & $46.4(1)$ & $+7.6(2)$ \\
\hline Duplex 4 & $\begin{array}{l}\text { 5'-GAGGGrAATGAAAG } \\
\text { 3'-CTCCCATACTTTC }\end{array}$ & - & $39.2(1)$ & - \\
\hline Duplex 4 & $\begin{array}{l}\text { 5'-GAGGGrAATGAAAG } \\
\text { 3'-CTCCCATACTTTC }\end{array}$ & $\mathrm{Ag}^{\mathrm{I}}$ & $40.2(4)$ & $+1.0(2)$ \\
\hline Duplex 5 & $\begin{array}{l}\text { 5'-GAGGGrCATGAAAG } \\
\text { 3'-CTCCCATACTTTAA }\end{array}$ & - & $39.8(1)$ & - \\
\hline Duplex 5 & $\begin{array}{l}\text { 5'-GAGGGrCATGAAAG } \\
\text { 3'-CTCCCATACTTTA }\end{array}$ & $\mathrm{Ag}^{\mathrm{I}}$ & $43.6(1)$ & $+3.8(1)$ \\
\hline Duplex 6 & 5'-GAGGGrCATGAAAG & - & $38.1(2)$ & - \\
\hline
\end{tabular}




\section{3'-CTCCССTACTTTA}
Duplex 6
5'-GAGGGrCATGAAAG
$\mathrm{Ag}^{\mathrm{I}}$
$42.4(4) \quad+4.3(3)$
3'-CTCCCCTACTTTA

[a] Standard deviations are given in parenthesis.

Having established the possibility of constructing RNA-DNA chimeric metal base pairs with synthetic oligonucleotides, we next sought to evaluate whether this could be translated to enzymatic synthesis. To do so, we carried out primer extension (PEX) reactions with templates containing a stretch of seven consecutive dT (T1), dC (T2), or dA (T3) nucleotides immediately $5^{4}$-downstream to the $3^{\text {'-end }}$ of fluorescently-labelled primer P1 (Table 2). ${ }^{49}$ Initial PEX reactions were carried out with five different commercially available DNA polymerases (Taq, Bst, Vent (exo'), Sulfolobus DNA Polymerase IV (Dpo4), and the Klenow fragment of DNA

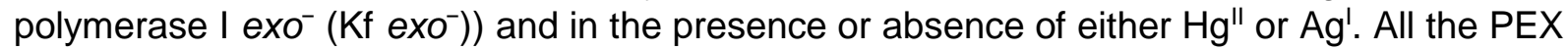
reaction products were analyzed by $20 \%$ denaturing gel electrophoresis and visualised using fluorescence imaging.

Table 2. Primer and templates used for primer extension reactions.

\begin{tabular}{ll}
\hline Name & Sequence \\
\hline P1 & 5'-FAM-CAT GGG CGG CAT GGG \\
T1 & 5'-TTT TTT TCC CAT GCC GCC CAT G \\
T2 & 5'-CCC CCC CCC CAT GCC GCC CAT G \\
T3 & 5'-AAA AAA ACC CAT GCC GCC CAT G \\
T4 & 5'-GGG GGG GCC CAT GCC GCC CAT G \\
\hline
\end{tabular}

Expectedly, all DNA polymerases investigated were capable of incorporating one (for Bst) or multiple deoxythymidine monophosphate (dTMP) units opposite templating dT nucleotides in the presence of $\mathrm{Hg}^{\mathrm{Il}}$ when the primer/template P1/T1 system was used (Figure S1). Moreover, when PEX reactions were conducted in the presence of both rUTP and $\mathrm{Hg}^{\prime \prime}$, partial incorporation of a single uridine monophosphate (UMP) moiety could be observed when Kf exo $0^{-}$was used as a polymerase, albeit in modest yields ( 20\%). The control reaction performed in absence of the metal cation did not yield any extended primer product. When the reaction mixtures were supplemented with the $\mathrm{Mn}^{\|}$cofactor which is known to relax polymerase fidelity ${ }^{50}$ and favor the formation of mercury metal mediated base pairs, ${ }^{40}$ the yield of $n+1$ product formation significantly increased to $\sim 50 \%$ (Figure S2). In order to confirm that $\mathrm{Mn}^{\text {"l }}$ was not implicated in metal base pair formation but served to improve the substrate tolerance of the polymerase, we recorded UV-melting experiments with duplexes containing homo- and hetero-mismatches (dT-dT and rU-dT) in the presence of Mn". The addition of this metal cation had little effect on the $T_{\mathrm{m}}$ values of duplexes 2 and 3, confirming that $\mathrm{Mn}^{\text {"l does }}$ not trigger metal base pair formation in duplex DNA. This is further confirmed by the small decrease in $T_{\mathrm{m}}$ observed when duplexes 2 and 3 were supplemented both with $\mathrm{Mn}^{\prime \prime}$ and $\mathrm{Hg}^{\prime \prime}$ instead of $\mathrm{Hg}^{\prime \prime}$ alone $\left(-0.8\right.$ and $-0.7^{\circ} \mathrm{C}$, respectively).

Based on these observations, we next sought to fine tune the experimental conditions to improve both yields and number of incorporation events (Figure 1). When both the reaction time and the UTP concentration were increased, full conversion of the primer to the $n+1(\sim 10 \%)$ and $\mathrm{n}+2(\sim 90 \%)$ products could be achieved when $\mathrm{Hg}^{\prime \prime}$ and $\mathrm{Mn}$ " were present (Figure 1D). In 
addition, no incorporation of a uridine moiety into DNA could be observed in the absence of $\mathrm{Hg}^{\prime \prime}$, underscoring the need for metal base-pair formation for the incorporation of this mismatched RNA nucleotide into DNA. We have also carried out PEX reactions with templates T1-T4 and the corresponding, complementary, NTPs (Figure S3) under similar experimental conditions. This analysis reveals that two UMPs are appended on the 3'-end of primer P1 when a template containing seven dA units was used (template T3) with a comparable efficiency to that of the misincoporation of UMPs opposite templating dT units triggered by mercury cations (Figure $1 \mathrm{C}$ and 1D). Surprisingly, $\mathrm{Kf} e \mathrm{ex}^{-}$was capable of appending up to 7 rNMP units onto primer $\mathrm{P} 1$ when templates $\mathrm{T} 1, \mathrm{~T} 2$, and T4 were used in PEX reactions in conjunction with the corresponding nucleoside triphosphate (Figure S3), confirming earlier findings that Pol I can incorporate ribonucleotides in vitro. ${ }^{27}$

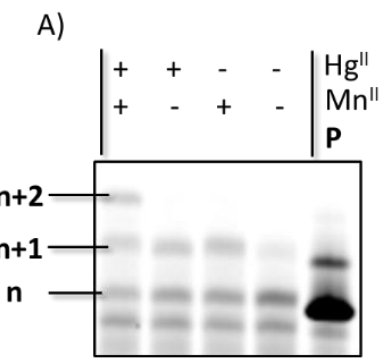

B)

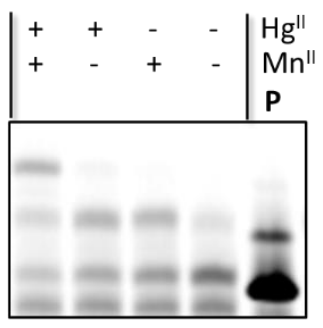

C)

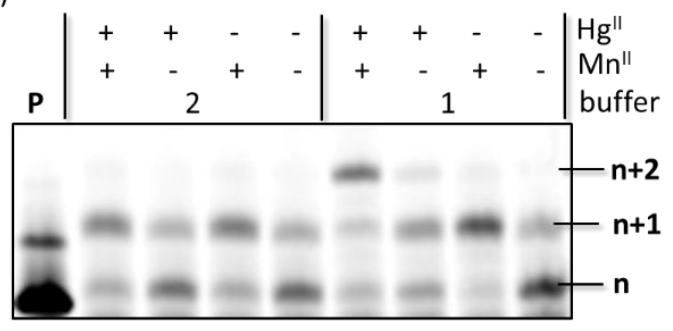

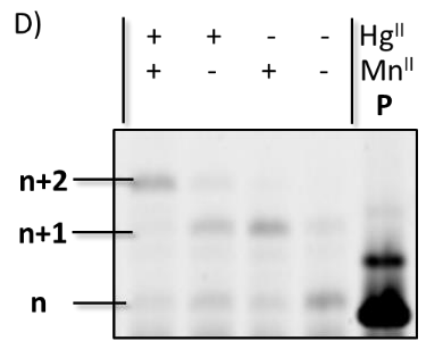

Figure 1. Gel images (PAGE 20\%) of PEX reactions carried out with primer P1 and template T1 using different UTP concentrations, reaction times, and metal cations. All reactions were performed with $5 \mathrm{U}$ of $\mathrm{Kf} e x 0^{-}$at $37^{\circ} \mathrm{C} . \mathrm{A}$ ) reactions with $200 \mu \mathrm{M}$ UTP and $3 \mathrm{~h}$ reaction time in buffer 1 ; B) reactions with 400 $\mu \mathrm{M}$ UTP and $3 \mathrm{~h}$ reaction time in buffer 1 ; C) reactions with $200 \mu \mathrm{M}$ UTP and $12 \mathrm{~h}$ reaction time; D) reactions in buffer 1 with $400 \mu \mathrm{M}$ UTP and $12 \mathrm{~h}$ reaction time. $5 \mathrm{U}$ of $\mathrm{Kf} \mathrm{exO}^{-}$were used in all reactions. Buffer 1 did not contain any source of $\mathrm{Cl}^{-}$and buffer 2 is the supplied buffer. In all cases, $\mathrm{Hg}\left(\mathrm{ClO}_{4}\right)_{2}$ was used as source of mercury. $\mathbf{P}$ indicates unreacted primer.

Having established conditions that enable the enzymatic formation of an $\mathrm{rU}-\mathrm{Hg}{ }^{\prime \prime}-\mathrm{dT}$ base pair, we next questioned whether this metal base pair could be bypassed once installed so that DNA synthesis could resume. ${ }^{51}$ To do so, we carried out PEX reactions with the $\mathrm{P} 1 / \mathrm{T} 1$ system and UTP to install rU-Hg"-dT base pairs (Figure 2A). The resulting products were then incubated with dTTP and Hg" (Figure 2B) or dATP (Figure 2C). Full length products could be observed upon the addition of dATP, suggesting that the rU-Hg"-dT base pairs did not induce termination of DNA synthesis. On the other hand, formation of dT-Hg" $-\mathrm{dT}$ base pair after the installation of the hetero-metal base pair only proceeded in low yields. 


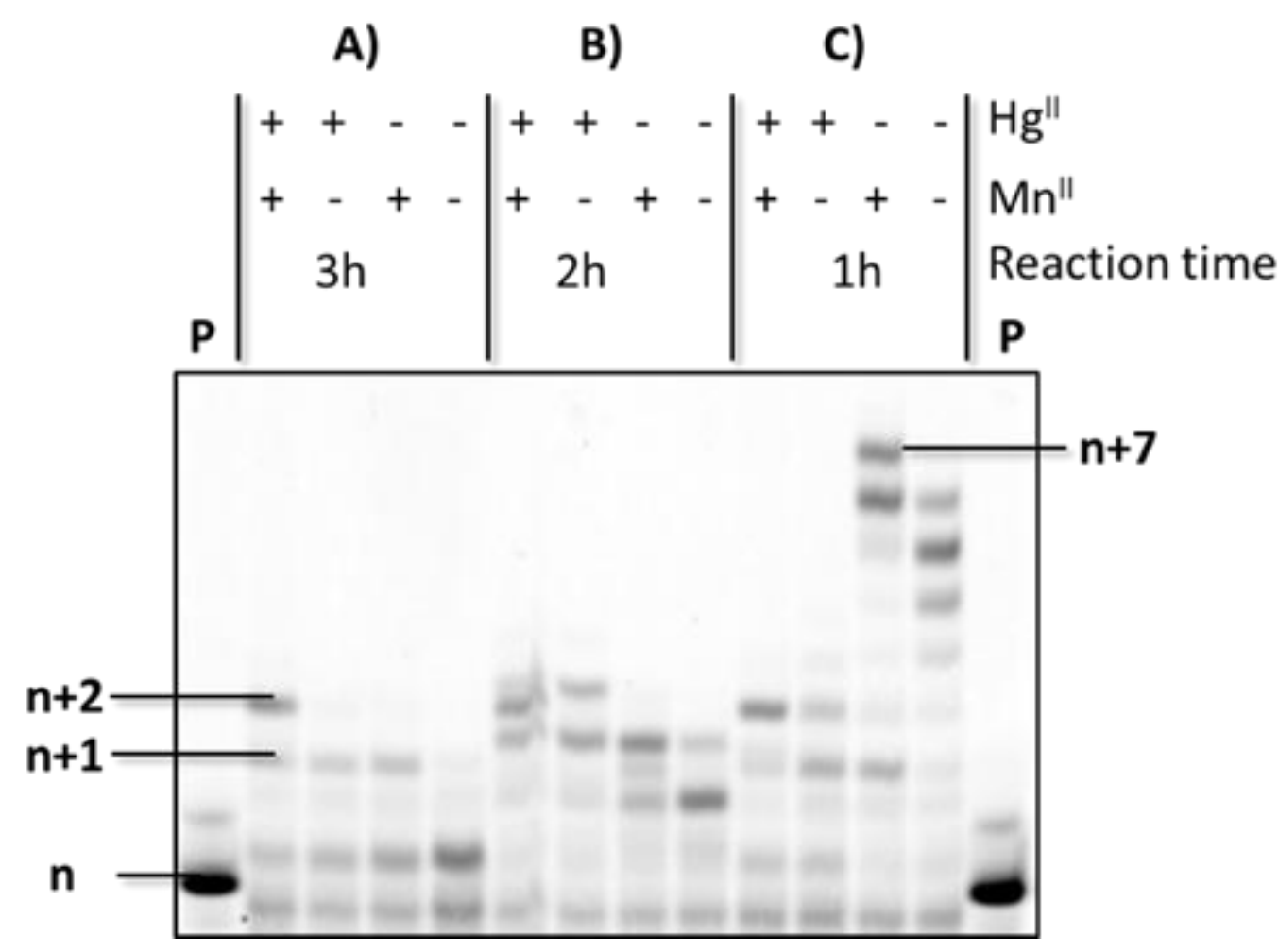

Figure 2. Gel analysis (PAGE 20\%) of products from the bypass experiments carried out with the primer $\mathrm{P} 1 /$ template $\mathrm{T} 1$ system. A) reactions with UTP $(400 \mu \mathrm{M})$ and $\mathrm{Kf} \mathrm{exO^{- }}(5 \mathrm{U})$ at $37^{\circ} \mathrm{C}$; B) reaction with UTP $(400 \mu \mathrm{M})$ and $\mathrm{Kf} e x \mathrm{O}^{-}(5 \mathrm{U})$ at $37^{\circ} \mathrm{C}$ for $3 \mathrm{~h}$ followed by addition of dTTP $(200 \mu \mathrm{M})$ and reaction $37^{\circ} \mathrm{C}$ for $\left.2 \mathrm{~h} ; \mathrm{C}\right)$ reaction with UTP $(400 \mu \mathrm{M})$ and $\mathrm{Kf}$ exo $(5 \mathrm{U})$ at $37^{\circ} \mathrm{C}$ for $3 \mathrm{~h}$ followed by addition of dATP $(200 \mu \mathrm{M})$ and reaction $37^{\circ} \mathrm{C}$ for $1 \mathrm{~h}$. $\mathbf{P}$ indicates unreacted primer.

Having established the possibility of forming rU-Hg"-dT base pairs, we next considered the possibility of using $\mathrm{Ag}^{+}$to trigger the formation of DNA/RNA hetero base pairs. UV melting experiments revealed that the $\mathrm{rC}-\mathrm{dA}$ and $\mathrm{rC}-\mathrm{dC}$ mismatches could be stabilized by the addition of $\mathrm{Ag}^{\prime}$, albeit to a lesser extent than rU-dT mismatches with $\mathrm{Hg}^{\prime \prime}$. Nonetheless, we attempted to use CTP as a substrate for polymerases to enzymatically construct rC-Ag'-dA and rC-Ag'$\mathrm{dC}$ base pairs since similar syntheses have been reported for the corresponding DNA base pairs. ${ }^{43-45}$ We thus carried out $\mathrm{PEX}$ reactions with the primer/template systems $\mathrm{P} 1 / \mathrm{T} 2$ (Figure S4) and P1/T3 (Figure S5) in the presence of different DNA polymerases and Ag'. Even by changing multiple reaction parameters (CTP concentration, reaction times) we could not observe any difference with the control reactions carried out in absence of metal cofactor and the incorporation of the RNA nucleotide remained modest. These results suggest that the strength of the rC-Ag'-dA and rC-Ag'-dC base pairs might not be sufficient to coerce the introduction of RNA nucleotides into DNA duplexes under enzymatic conditions. Finally, PEX reactions with ATP with primer $\mathrm{P} 1$ and template $\mathrm{T} 3$ did not lead to the formation of $n+1$ products (data not shown) suggesting that a silver mediated base pair is not formed due to the rather modest duplex stability observed in UV melting experiments (duplex 4 in Table 1).

\section{Conclusions}

In conclusion, we have investigated the possibility of using the favorable thermodynamic and kinetic parameters of metal base pair formation to insert RNA nucleotides into an all-DNA setting using DNA polymerases. In a first step towards this aim, we have used UV melting 
experiments on short synthetic duplexes to confirm the possibility of forming rU-Hg" $-\mathrm{dT}$ base pairs. These mercury-mediated base pairs stabilized mismatched duplexes albeit to a slightly lesser extent than the parent $\mathrm{dT}-\mathrm{Hg}^{\mathrm{II}}-\mathrm{dT}$ base pair. A similar trend was observed with a duplex containing an rC-Ag'-dC base pair but not with $\mathrm{rC}-\mathrm{Ag}^{\prime}-\mathrm{dC}$ which is less stable than in the allDNA case. These trends are reflected in PEX reactions using natural RNA nucleotides since efficient $\mathrm{rU}-\mathrm{Hg}^{\mathrm{I}}-\mathrm{dT}$ base pair formation could be observed. On the other hand, the stability of silver-mediated pairs appeared to be insufficient to coerce DNA polymerases to misincorporate RNA nucleotides even in the presence of metal cations. Taken together, the favorable kinetic and thermodynamic parameters of mercury-mediated base pairs can be hijacked to generate RNA-DNA oligonucleotides using polymerase-assisted synthesis. Such an approach alleviates the synthetic efforts required for the generation of such chimeric oligonucleotides which are used in numerous applications such as substrates for DNAzyme selections. ${ }^{52,}{ }^{53}$ Finally, we are currently investigating the compatibility of other sugar chemistries with the enzymatic synthesis of artificial metal base pairs in order to eventually achieving our long standing aim of creating orthogonal xenonucleic acids based on metal base pairs. ${ }^{54}$

\section{Conflicts of interest}

There are no conflicts to declare

\section{Acknowledgements}

Institut Pasteur (starting funds to M.H.) and The Joe W. and Dorothy Doresett Brown Foundation (research grants to M.H.) are acknowledged for funding. L. K. M. thanks the ARC Foundation for cancer research for a postdoctoral Research Fellowship (grant number: SFB18006).

\section{Notes and references}

1. J. Müller, Coord. Chem. Rev., 2019, 393, 37-47.

2. Y. Tanaka, J. Kondo, V. Sychrovský, J. Šebera, T. Dairaku, H. Saneyoshi, H. Urata, H. Torigoe and A. Ono, Chem. Commun., 2015, 51, 17343-17360.

3. K. Kowalski, Coord. Chem. Rev., 2021, 432, 213705.

4. G. H. Clever, C. Kaul and T. Carell, Angew. Chem. Int. Ed., 2007, 46, 6226-6236.

5. A. Perez-Romero, A. Dominguez-Martin, S. Galli, N. Santamaria-Diaz, O. Palacios, J. A. Dobado, M. Nyman and M. A. Galindo, Angew. Chem. Int. Ed., 2021, 60, 1008910094.

6. A. Gonzalez-Rosell, C. Cerretani, P. Mastracco, T. Vosch and S. M. Copp, Nanoscale Adv., 2021, 3, 32.

7. A. Aro-Heinila, T. Lönnberg and P. Virta, ChemBioChem, 2021, 22, 354-358.

8. J. Kondo, Y. Tada, T. Dairaku, Y. Hattori, H. Saneyoshi, A. Ono and Y. Tanaka, Nat. Chem., 2017, 9, 956-960.

9. A. Ono, H. Kanazawa, H. Ito, M. Goto, K. Nakamura, H. Saneyoshi and J. Kondo, Angew. Chem. Int. Ed., 2019, 58, 16835-16838.

10. X. L. Zhou, D. Kondhare, P. Leonard and F. Seela, Chem.-Eur. J., 2019, 25, 1040810419.

11. Y. Takezawa, A. Suzuki, M. Nakaya, K. Nishiyama and M. Shionoya, J. Am. Chem. Soc., 2020, 142, 21640-21644.

12. M. H. Heddinga and J. Müller, Beilstein J. Org. Chem., 2020, 16, 2870-2879.

13. Y. Takezawa, L. Y. Hu, T. Nakama and M. Shionoya, Angew. Chem. Int. Ed., 2020, 59, 21488-21492. 
14. T. Nakama, Y. Takezawa, D. Sasaki and M. Shionoya, J. Am. Chem. Soc., 2020, 142, 10153-10162.

15. L. K. McKenzie, R. El-Khoury, J. D. Thorpe, M. J. Damha and M. Hollenstein, Chem. Soc. Rev., 2021, 50, 5126-5164.

16. M. Flamme, C. Figazzolo, G. Gasser and M. Hollenstein, Metallomics, 2021, 13.

17. T. Kobayashi, Y. Takezawa, A. Sakamoto and M. Shionoya, Chem. Commun., 2016, 52, 3762-3765.

18. C. Kaul, M. Müller, M. Wagner, S. Schneider and T. Carell, Nat. Chem., 2011, 3, 794800.

19. E.-K. Kim and C. Switzer, ChemBioChem, 2013, 14, 2403-2407.

20. B. Jash, P. Scharf, N. Sandmann, C. Fonseca Guerra, D. A. Megger and J. Müller, Chem. Sci., 2017, 8, 1337-1343.

21. L. Zhang and E. Meggers, J. Am. Chem. Soc., 2005, 127, 74-75.

22. Z. Ma, F. Olechnowicz, Y. A. Skorik and C. Achim, Inorg. Chem., 2011, 50, 6083-6092.

23. O. Nakagawa, H. Aoyama, A. Fujii, Y. Kishimoto and S. Obika, Chem.-Eur. J., 2021, 27, 3842-3848.

24. E. Medina, E. J. Yik, P. Herdewijn and J. C. Chaput, ACS Synth. Biol., 2021, DOI: 10.1021/acssynbio.1c00048.

25. W.-J. Wu, W. Yang and M.-D. Tsai, Nat. Rev. Chem., 2017, 1, 0068.

26. C. M. Joyce, Proc. Natl. Acad. Sci. U.S.A., 1997, 94, 1619-1622.

27. M. Astatke, K. M. Ng, N. D. F. Grindley and C. M. Joyce, Proc. Natl. Acad. Sci. U.S.A., 1998, 95, 3402-3407.

28. Z. X. Zhou, J. S. Williams, S. A. Lujan and T. A. Kunkel, Crit. Rev. Biochem. Mol. Biol., 2021, 56, 109-124.

29. S. A. N. McElhinny, B. E. Watts, D. Kumar, D. L. Watt, E. B. Lundstrom, P. M. J. Burgers, E. Johansson, A. Chabes and T. A. Kunkel, Proc. Natl. Acad. Sci. U.S.A., 2010, 107, 4949-4954.

30. S. Ohashi, F. Hashiya and H. Abe, ChemBioChem, 2021, DOI: https://doi.org/10.1002/cbic.202100004, 10.1002/cbic.202100004.

31. A. F. Gardner, K. M. Jackson, M. M. Boyle, J. A. Buss, V. Potapov, A. M. Gehring, K. M. Zatopek, I. R. Correa, J. L. Ong and W. E. Jack, Front. Mol. Biosci., 2019, 6, 9.

32. T. Chen, N. Hongdilokkul, Z. Liu, R. Adhikary, S. S. Tsuen and F. E. Romesberg, Nat. Chem., 2016, 8, 556-562.

33. Y. Miyake, H. Togashi, M. Tashiro, H. Yamaguchi, S. Oda, M. Kudo, Y. Tanaka, Y. Kondo, R. Sawa, T. Fujimoto, T. Machinami and A. Ono, J. Am. Chem. Soc., 2006, 128, 2172-2173.

34. O. P. Schmidt, G. Mata and N. W. Luedtke, J. Am. Chem. Soc., 2016, 138, 1473314739.

35. S. Johannsen, S. Paulus, N. Düpre, J. Müller and R. K. O. Sigel, J. Inorg. Biochem., 2008, 102, 1141-1151.

36. S. Manna and S. G. Srivatsan, Org. Lett., 2019, 21, 4646-4650.

37. T. Kozasa, Y. Miyakawa, A. Ono and H. Torigoe, Nucleic Acids Symp. Ser., 2008, 52, 197-198.

38. H. Torigoe, Y. Miyakawa, A. Ono and T. Kozasa, Thermochim. Acta, 2012, 532, 28-35.

39. H. Urata, E. Yamaguchi, T. Funai, Y. Matsumura and S. Wada, Angew. Chem. Int. Ed., 2010, 49, 6516-6519.

40. T. Funai, C. Tagawa, O. Nakagawa, S. Wada, A. Ono and H. Urata, Chem. Commun., 2020, 56, 12025-12028.

41. A. Ono, S. Cao, H. Togashi, M. Tashiro, T. Fujimoto, T. Machinami, S. Oda, Y. Miyake, I. Okamoto and Y. Tanaka, Chem. Commun., 2008, 4825-4827.

42. J. Kondo, Y. Tada, T. Dairaku, H. Saneyoshi, I. Okamoto, Y. Tanaka and A. Ono, Angew. Chem. Int. Ed., 2015, 54, 13323-13326.

43. T. Funai, Y. Miyazaki, M. Aotani, E. Yamaguchi, O. Nakagawa, S. Wada, H. Torigoe, A. Ono and H. Urata, Angew. Chem. Int. Ed., 2012, 51, 6464-6466. 
44. T. Funai, J. Nakamura, Y. Miyazaki, R. Kiriu, O. Nakagawa, S. Wada, A. Ono and H. Urata, Angew. Chem. Int. Ed., 2014, 53, 6624-6627.

45. T. Funai, M. Aotani, R. Kiriu, J. Nakamura, Y. Miyazaki, O. Nakagawa, S. Wada, H. Torigoe, A. Ono and H. Urata, ChemBioChem, 2020, 21, 517-522.

46. B. Jash, J. Neugebauer and J. Müller, Inorg. Chim. Acta, 2016, 452, 181-187.

47. S. Naskar and J. Müller, Chem.-Eur. J., 2019, 25, 16214-16218.

48. H. Torigoe, I. Okamoto, T. Dairaku, Y. Tanaka, A. Ono and T. Kozasa, Biochimie, 2012, 94, 2431-2440.

49. P. Röthlisberger, F. Levi-Acobas, I. Sarac, R. Ricoux, J. P. Mahy, P. Herdewijn, P. Marliere and M. Hollenstein, Tetrahedron Lett., 2018, 59, 4241-4244.

50. P. Röthlisberger, F. Levi-Acobas, I. Sarac, P. Marliere, P. Herdewijn and M. Hollenstein, Org. Biomol. Chem., 2017, 15, 4449-4455.

51. M. Flamme, P. Röthlisberger, F. Levi-Acobas, M. Chawla, R. Oliva, L. Cavallo, G. Gasser, P. Marliere, P. Herdewijn and M. Hollenstein, ACS Chem. Biol., 2020, 15, 2872-2884.

52. M. Hollenstein, Curr. Opin. Chem. Biol., 2019, 52, 93-101.

53. Y. J. Wang, K. Nguyen, R. C. Spitale and J. C. Chaput, Nat. Chem., 2021, 13, 13.

54. J. C. Chaput, P. Herdewijn and M. Hollenstein, ChemBioChem, 2020, 21, 1408-1411. 